\title{
Rex M. Oppenheimer (author), Peter Bela Fodor (medical editor), and Bill Winn (illustrator): Be Your Best: A Comprehensive Guide to Aesthetic Plastic Surgery
}

\author{
Insight International Press, LLC, Austin, TX, 1st edn., 288 pp
}

\author{
Thomas M. Biggs
}

Published online: 24 April 2010

(C) Springer Science+Business Media, LLC and International Society of Aesthetic Plastic Surgery 2010

The opening lines of the first page of this book state that it is a different kind of book, that it is written for the intelligent consumer who is interested in getting a full understanding of aesthetic surgery. This is a true statement. The compilation of the thoughts of 100 board-certified plastic surgeons covering all the components of aesthetic plastic surgery gives the intelligent consumer an immense amount of information in an easily understandable prose. Each chapter has a brief "Fast Facts" bar that gives a concise résumé of the information presented, and at the end of each chapter there is a summation from the perspective of the Editor's immense reservoir of experience.
It is true that this book is different. It is true that it can be of great benefit to the intelligent consumer in sorting out the complexities of aesthetic surgery. However, it is also different in that it could clear up some of the confusion experienced by all beginning residents in plastic surgery. It is different in that it could be an excellent gift from a training program to the applicant who has just been accepted into the residency. It is different also in the fact that the professor who peruses its pages will, as I, with over 50 years of practicing plastic surgery and reading more than my share of literature, find that it contains some new perspectives and stimulating new thoughts. This is a different kind of book.

T. M. Biggs ( $\square)$

1315 St. Joseph Parkway, Suite 900, Houston, TX 77002, USA

e-mail: tbiggsmd@aol.com 